\section{MICROBIOLOGY AND DRUG RESISTANCE PATTERN IN CLINICALLY SIGNIFICANT ISOLATES OF URINE FROM MEDICAL WARDS OF A TERTIARY CARE HOSPITAL IN NORTH INDIA.}

KEY WORDS: UTI, MDR organisms causing UTI, E coli, bacterial etiology of UTI, Hospital acquired UTI

\section{Dr Saqib Rishi}

\section{Dr Nahid Nahvi}

\section{Dr Arshid Rasool Wani}

Senior Resident, Department Of Microbiology, Government Medical College, Srinagar Kashmir India.

Professor, Department Of Microbiology, Government Medical College, Srinagar Kashmir India.

\section{Pg Scholar, Department Of Anaesthesiology, ASCOMS Jammu India.}

Department Of Microbiology, Government Medical College, Srinagar Kashmir India. *Corresponding Author

Urinary tract infections (UTIs) are one of the most common bacterial infections encountered in clinical practice both in community and hospital settings in all age groups. It is the second most frequently occurring infection in general population after upper respiratory tract infection. Urinary tract infections (UTIs) are the leading cause of Gram negative sepsis in hospitalized patients and are the origin for about half of all hospital acquired infections caused by urinary catheters and are associated with considerable cost in terms of morbidity and economic and research expenditure. Material And Methods: This prospective cross sectional study was carried out in the Department of Microbiology of Government Medical College, Srinagar. A total of 800 patients were taken up for the study. The sample falling under the set inclusion criteria were selected from the urine specimen received in the laboratory for urine culture and sensitivity from Hospitalized patients (IPD). Culture and sensitivity reports and patient data obtained from hospital records was analyzed for this study. Results: Out of 800 samples taken up for the study $208(26 \%)$ were culture positive and 592 (74\%) were negative. 208 positive samples $125(60.10 \%)$ were females and $83(39.90 \%)$ were males. female predominance was observed with $71 \%$ whereas $29 \%$ males were affected by UTI. UTI was predominantly in females of age group (21-40 yrs). most common organism isolated on culture was Escherichia coli(43.26\%) both in short stay patients (<48hrs hospital stay) /OPD $22.59 \%$ as well as in IPD (>48hrs hospital stay) $20.67 \%$.E.coli was isolated from patients of both uncomplicated and complicated UTI. The second most common organism isolated in our study was Enterococcus faecalis $(22.59 \%$ ), the rate of isolation was much higher $18.75 \%$ in inpatients (>48hrs hospital stay) and only $3.84 \%$ in OPD/short stay patients (<48hrs hospital stay). In our study Enterococcus spp ranked second amongst uropathogens, in IPD patients isolation rate was almost 5 times higher. Pseudomonas spp was 1 isolate in OPD $(0.48 \%)$ and $6(2.88 \%)$ in IPD, Acinetobacter $3(1.44 \%)$, Proteus $1(0.48 \%)$ found only in hospitalized patients (stay $>48 \mathrm{hrs}$ ). E.coli showed following sensitivity pattern $96.7 \%$ to nitrofurantoin, $93.3 \%$ to imipenem, $90.0 \%$ to amikacin, $75.6 \%$ to gentamycin, $73.3 \%$ to cefoperazone-salbactam and meropenem both, $68.9 \%$ to pipercillin tazobactam. The sensitivity to TMP-SMX was $45.6 \%$, and to ceftriaxone and cefipime was only $22.2 \%$ and $21.1 \%$ respectively. The organism also showed resistance to drugs like levofloxacin $82.2 \%$ and ciprofloxacin $76.7 \%$.Enterococcus faecalis isolated in our study was sensitive to Vancomycin 95.74\% followed by Linezolid (93.6\%), Nitrofurantoin (78.7\%), HL-Amikacin (74.5\%),HLGentamycin (70.2\%). Enterococcus faecalis showed resistance to drugs commonly used to treat UTI i.e. $91.5 \%$ resistant to Ciprofloxacin and $89.4 \%$ resistant to Levofloxacin. Conclusion: Gram negative bacteria were most predominant microorganisms resulting in more than $50 \%$ infections causing urinary tract infection. In our study we have seen that Gram positive cocci especially Enterococcus result in UTI in a significant proportion of patients. In our study Enterococcus spp ranked second amongst uropathogens, in IPD patients isolation rate was almost 5 times higher. The implementation of antibiotic stewardship programs is crucial to minimize resistance. Appropriate antibiotics need to be prescribed based on the antibiotic susceptibility testing which will be narrow spectrum, effective and less expensive with least side effects.

\section{INTRODUCTION:}

Urinary tract infection (UTI) is defined as microbial invasion of any of the tissues of the urinary tract extending from the renal cortex to urethral meatus ${ }^{(1)}$. The term urinary tract infection encompasses a variety of clinical entities, including asymptomatic bacteriuria (ASB), cystitis, prostatitis, and pyelonephritis $^{(2)}$. Clinically, UTIs are categorized as uncomplicated or complicated. Uncomplicated UTIs typically affect individuals who are otherwise healthy and have no structural or neurological urinary tract abnormalities. These infections are differentiated into lower UTIs (cystitis) characterized by dysuria, frequency, urgency, and occasionally suprapubic tenderness and upper UTIs (pyelonephritis) characterized by flank pain, tenderness, or both, and fever, often associated with dysuria, urgency, and frequency. Several risk factors are associated with cystitis, including female gender, a prior UTI, sexual activity, vaginal infection, diabetes, obesity and genetic susceptibility. Complicated UTIs are defined as UTIs associated with factors that compromise the urinary tract or host defense, including urinary obstruction, urinary retention caused by neurological disease, immunosuppression, renal failure, renal transplantation, pregnancy and the presence of foreign bodies such as calculi, indwelling catheters or other drainage devices $^{(384) .}$ In general, infection in men, pregnant women, children, and patients who are hospitalized or in health care associated settings may be considered complicated. Complicated hospital acquired urinary tract infections (UTIs) are generally caused by multidrug resistant organisms. Urinary tract infections (UTIs) can recur in the form of relapses or re-infections. Relapse of bacteriuria refers to a recurrence of bacteriuria with the same infecting microorganism that was present before therapy was started. This is caused by the persistence of the organism in the urinary tract. Re-infection on the other hand is a recurrence of bacteriuria with a microorganism different from the original infecting bacterium. Re-infection may occur with the same microorganism, which may have persisted in the vagina or 
feces and can be mistaken for a relapse ${ }^{(5)}$.

Urinary tract infection (UTI) is associated with multiplication of organisms in the urinary tract ${ }^{(1)}$. The ability of the urinary tract to defend against microbial infections is dependent on its normal anatomic structure and its functional physiological state. The forward flow of urine is one of the important factors for the maintenance of a healthy urinary tract. Any structural or functional process that interrupts the flow of urine leads to urine stasis, and hence to Urinary tract infection (UTI) ${ }^{(6)}$. Also the urethra has resident microbiota that colonize its epithelium in the distal portion; these organisms are Coagulase-negative staphylococci (excluding Staphylococcus saprophyticus) Viridans and non-hemolytic streptococci Lactobacilli (adult females) Diphtheroids (Corynebacterium spp.) Nonpathogenic (saprobic) Neisseria spp. (adult women) Anaerobic cocci Propionibacterium spp. (adult patients)Commensal Mycobacterium spp. Commensal Mycoplasma spp. Yeasts (pregnant, adult females). The resident microbiota predominantly Lactobacilli produce lactic acid, which creates a low $\mathrm{pH}$ condition that is highly unfavorable for the growth and colonization by uropathogenic microbes and hence is one of the major host defenses, as alterations in resident flora are considered a predisposing factor to UTIs ${ }^{(5)}$. Potential pathogens, primarily Enterobacteriaceae and least likely yeasts may be present as transient colonizers. Whole of the urinary tract above the urethra is sterile in a healthy human and urine thus formed remains sterile. Uropathogenic microbes possess various virulence factors that enhance their ability to colonize and invade the urinary tract. Some of these virulence factors include increased adherence to vaginal and uroepithelial cells by bacterial surface structures (adhesins), pili (P [PAP] type 1), and multiple types of fimbriae; the production of alpha-hemolysin (inhibits the production of protective cytokines), cytotoxic necrotizing factor (CNF), an auto transported protease (Sat), aerobactin (iuc), and a siderophore receptor (iroN); and resistance to serum-killing activity ${ }^{(1)}$.Urinary tract infection (UTI) is defined as microbial invasion of any of the tissues of the urinary tract extending from the renal cortex to urethral meatus ${ }^{(1)}$.The term urinary tract infection encompasses a variety of clinical entities, including asymptomatic bacteriuria (ASB), cystitis, prostatitis, and pyelonephritis ${ }^{(2)}$. Both urinary tract infection (UTI) and asymptomatic bacteriuria (ASB) denote the presence of bacteria in the urinary tract, usually accompanied by white blood cells and inflammatory cells in the urine ${ }^{(8)}$. Bacteriuria is a frequently used term that denotes the presence of bacteria in urine. The probability of the presence of bacteriuria can be ascertained by quantifying the number of bacteria in voided urine or in urine obtained via urethral catheterization. Significant bacteriuria is a term used to describe the number of bacteria in voided urine that usually exceeds the number caused by contamination from the anterior urethra (i.e., $\geq 10^{5}$ bacteria $/ \mathrm{ml}$ ). The implication being that in the presence of at least $10^{5}$ bacteria/ml of urine, infection must be seriously considered ${ }^{(8)}$. However studies of women with symptoms of cystitis have found that a colony count threshold of $\geq 10^{2}$ bacteria/mL is more sensitive (95\%) and specific $(85 \%)$ than a threshold of $10^{5} / \mathrm{mL}$ for the diagnosis of acute cystitis in women. In men, the minimal level indicating infection appears to be $10^{3} / \mathrm{mL}^{(8)}$.

Urinary tract infections (UTIs) are one of the most common bacterial infections encountered in clinical practice both in community and hospital settings in all age groups ${ }^{(9)}$. It is the second most frequently occurring infection in general population after upper respiratory tract infection ${ }^{(10)}$. Urinary tract infections (UTIs) are the leading cause of Gram negative sepsis in hospitalized patients and are the origin for about half of all hospital acquired infections caused by urinary catheters (11) and are associated with considerable cost in terms of morbidity and economic and research expenditure ${ }^{(12)}$.The hospital acquired urinary tract infections accounts to about
$40 \%$ of the hospital acquired infections. Long term hospitalized patients with indwelling urinary catheters and patients undergoing urological treatment are prone to hospital acquired infections ${ }^{(13)}$. In ambulatory persons who undergo a single catheterization risk of UTI in only about $1 \%$ while as after a single catheterization of hospitalized patients, infection occurs in at least $10 \%{ }^{(5)}$.Hospitalized patients are most likely to be infected by E.coli, Klebsiella spp., Proteus spp., Staphylococci, other Enterobacteriaceae, Pseudomonas aeruginosa, Enterococci, and Candida spp ${ }^{(11)}$.Since the last two to three decades urinary tract infections (UTIs) due to multidrug resistant uropathogens have caused a growing concern worldwide ${ }^{(14)}$.

\section{MATERIAL AND METHODS:}

This prospective cross sectional study was carried out in the Department of Microbiology of Government Medical College, Srinagar. A total of 800 patients were taken up for the study. The samples were selected randomly from the urine specimen received in the laboratory for urine culture and sensitivity. Hospitalized patients (IPD), Patients above the age of 2 years with suspected urinary tract infection, catheterized patients and patients who had under gone surgical instrumentation and patients on antibiotics were included in the study. Samples which were taken by following techniques: Suprapubic aspiration, Percutaneous nephrostomy (PCN aspirate), Cystoscopy and Ileal conduit were excluded from the study. Patients were advised to collect the midstream clean catch urine by voiding the first portion of urine. It is recommended that the midstream clean catch morning urine specimen be collected in a sterile, wide mouth, screw capped bottle after very thorough preliminary cleaning of external genitalia with soap and water. For Hospitalized patients with indwelling catheter Staff was advised to clamp off the catheter tubing above the port to allow the collection of freshly voided urine. The catheter port or wall of the tubing was then asked to be cleaned vigorously with $70 \%$ ethanol, and urine aspirated via a needle and syringe; it was advised to maintain the integrity of the closed drainage system to prevent the introduction of organisms into the bladder. If specimen was an intermittent catheter specimen it was advised that a red rubber catheter be introduced into the urethra periodically to drain urine from the bladder and collected directly into a specimen container. Urine was transported to the laboratory as soon as possible. It was cultured as early as possible after collection, preferably within 2 hours. In case of delay, it was advised to be refrigerated up to a maximum of 24 hours before plating as bacterial counts in refrigerated $\left(4^{\circ} \mathrm{C}\right)$ urine remain constant for as long as 24 hours. If delay was expected to be for more than 24 hours then use of transport media (Urine transport tubes containing boric acid, sodium borate, and sodium formate ) was advised.Direct Gram staining was performed and Smear was then examined under oil immersion (1000x).

The presence of 1 or 5 bacteria per oil immersion field (OIF) which is suggestive of significant bacteriuria.The specimen tubes were then placed in the refrigerator till plating and there after stored at $2-8^{\circ} \mathrm{C}$ until the final report was sent. For Culture the urine pot was turned over to mix it carefully and then the top of the container was removed. The end of a sterile calibrated loop designed to deliver a known volume, either 0.01 or $0.001 \mathrm{~mL}$ of urine was dipped into the urine and removed vertically making sure that there is no urine up the loop (as this would mean that a greater volume was cultured).The entire volume was spread over the surface of a $5 \%$ sheep blood agar plate and a MacConkey agar plate by making a single streak across the centre. The inoculum was evenly spread at right angles to the primary streak .Plates were incubated aerobically at $35-37^{\circ} \mathrm{C}$ for at $18-24$ hours. The characteristic colony character and colony count were taken into consideration. The organism were later confirmed using conventional biochemical techniques after doing gramstaining.The number of bacteria were estimated by counting 
the number of colonies on the surface of the media. One colony $=1,000 \mathrm{cfu} / \mathrm{mL}\left(1 \times 10^{3} \mathrm{cfu} / \mathrm{ml}\right)$ when we take $.001 \mathrm{ml}$ of urine and when a larger volume of urine i.e. .01 ml is used one colony $=100 \mathrm{cfu} / \mathrm{ml}\left(1 \times 10^{2} \mathrm{cfu} / \mathrm{ml}\right)$.If there was a pure growth of $10-100$ or over 100 colonies, the isolate was sub cultured for identification and antimicrobial susceptibility testing. For cultures that contained two organisms, one in low numbers $(<100$ colonies $)$ and the other over 100 colonies, then only the predominant organism was sub cultured because the organism of lower numbers is unlikely to be causing the disease. If both are present at over 100 colonies, both organisms were sub cultured. If more than two organisms were isolated, then further processing was not done since this is highly likely to be a contaminated specimen.Antimicrobial susceptibility testing were performed using the Kirby-Bauer disk diffusion method according to Clinical and Laboratory Standards Institute (CLSI). ${ }^{(15)}$ The antibiotic sensitivity for Gram positive organisms were put on Vitek-2 compact identification system (Biomerieux, USA) following the manufactures instructions.

\section{Table 7: Results Of Urine Culture}

\begin{tabular}{|l|l|l|}
\hline Culture & Frequency & Percent (\%) \\
\hline Positive & 208 & $26 \%$ \\
\hline Negative & 592 & $74 \%$ \\
\hline Total & 800 & $100 \%$ \\
\hline
\end{tabular}

Table 9: Gender Frequency Of Culture Positive Samples In Relation With Age.

\begin{tabular}{|l|l|l|l|}
\hline Age & Frequ \%age & Culture Positive \\
\cline { 2 - 2 } & &
\end{tabular}

\begin{tabular}{|c|c|c|c|c|c|c|}
\hline & \multirow{3}{*}{ ency } & & & & & \\
\hline & & & Male & & Female & \\
\hline & & & Frequency & \%age & Frequency & \%age \\
\hline$<10$ & 1 & $0.12 \%$ & 1 & $0.48 \%$ & - & - \\
\hline $11-20$ & 21 & $2.62 \%$ & 5 & $2.40 \%$ & 9 & $4.32 \%$ \\
\hline $21-40$ & 304 & $38 \%$ & 25 & $12.01 \%$ & 53 & $25.48 \%$ \\
\hline $40-60$ & 167 & $20.87 \%$ & 13 & $6.25 \%$ & 26 & $12.5 \%$ \\
\hline$>60$ & 307 & $38.37 \%$ & 39 & $18.75 \%$ & 37 & $17.78 \%$ \\
\hline Total & 800 & $100 \%$ & 83 & $39.89 \%$ & 125 & $60.08^{\circ}$ \\
\hline
\end{tabular}

Table 11: Gender Distribution Of Culture Positive Samples On The Basis Of Days Of Hospitalization

\begin{tabular}{|c|c|c|c|c|c|c|}
\hline \multirow{3}{*}{$\begin{array}{l}\text { Duratio } \\
n \text { of } \\
\text { stay }\end{array}$} & \multirow[t]{3}{*}{ Frequency } & \multirow[t]{3}{*}{ \%age } & \multicolumn{4}{|c|}{ Culture Positive } \\
\hline & & & \multicolumn{2}{|l|}{ Male } & \multicolumn{2}{|l|}{ Female } \\
\hline & & & Frequency & \%age & Frequency & \%age \\
\hline $\begin{array}{l}\text { OPD/ } \\
\text { short } \\
\text { stay } \\
<48 \mathrm{hrs}\end{array}$ & 124 & $\begin{array}{l}59.61 \\
\%\end{array}$ & 46 & $\begin{array}{l}37.09 \\
\%\end{array}$ & 78 & \begin{tabular}{|l|}
62.90 \\
$\%$
\end{tabular} \\
\hline $\begin{array}{l}\text { IPD }>48 \\
\text { hrs }\end{array}$ & 83 & $\begin{array}{l}39.90 \\
\%\end{array}$ & 37 & $\begin{array}{l}44.57 \\
\%\end{array}$ & 46 & \begin{tabular}{|l|}
55.42 \\
$\%$
\end{tabular} \\
\hline
\end{tabular}

\section{Fig 6 Culture Positives}

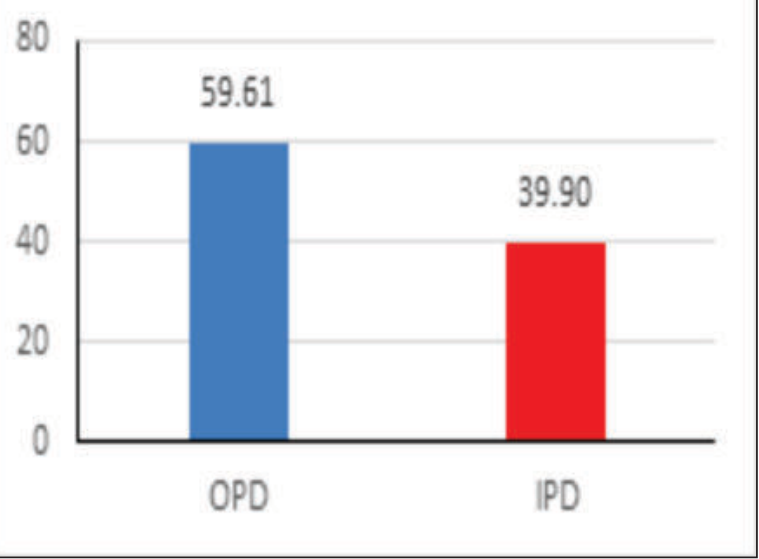

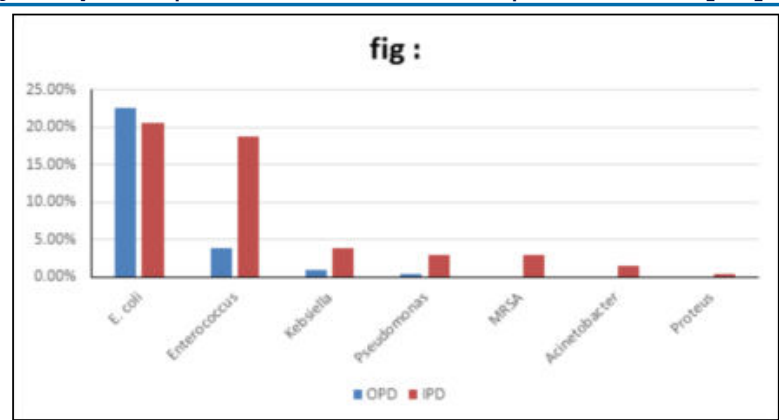

Table 16: Frequency Distribution Of Single Bacterial Isolates From Urine Culture

\begin{tabular}{|l|l|l|l|l|}
\hline Organisms isolated & OPD & $\%$ age & IPD & $\%$ age \\
\hline E.coli & 47 & $22.59 \%$ & 43 & $20.67 \%$ \\
\hline Enterococcus & 8 & $3.84 \%$ & 39 & $18.75 \%$ \\
\hline Kebsiella & 2 & $0.96 \%$ & 8 & $3.84 \%$ \\
\hline Pseudomonas & 1 & $0.48 \%$ & 6 & $2.88 \%$ \\
\hline MRSA & 0 & $0 \%$ & 6 & $2.88 \%$ \\
\hline Acinetobacter & 0 & $0 \%$ & 3 & $1.44 \%$ \\
\hline Proteus & 0 & $0 \%$ & 1 & $0.48 \%$ \\
\hline Total & 58 & $27.87 \%$ & 106 & $50.94 \%$ \\
\hline
\end{tabular}

Table 17: Antibiotic Sensitivity Of E. Coli

\begin{tabular}{|c|c|c|c|}
\hline Antibiotic & Sensitive & Resistant & Total \\
\hline \multirow[t]{2}{*}{ Amikacin } & 81 & 9 & 90 \\
\hline & $90.0 \%$ & $10.0 \%$ & $100.0 \%$ \\
\hline \multirow[t]{2}{*}{ Cefoperazone/Salbactam } & 66 & 24 & 90 \\
\hline & $73.3 \%$ & $26.7 \%$ & $100.0 \%$ \\
\hline \multirow[t]{2}{*}{ Ciprofloxacin } & 21 & 69 & 90 \\
\hline & $23.3 \%$ & $76.7 \%$ & $100.0 \%$ \\
\hline \multirow[t]{2}{*}{ Cefepime } & 19 & 71 & 90 \\
\hline & $21.1 \%$ & $78.9 \%$ & $100.0 \%$ \\
\hline \multirow{2}{*}{$\begin{array}{l}\text { Trimethoprim- } \\
\text { Sulfamethoxazole }\end{array}$} & 41 & 49 & 90 \\
\hline & $45.6 \%$ & $54.4 \%$ & $100.0 \%$ \\
\hline \multirow[t]{2}{*}{ Ceftriaxone } & 20 & 70 & 90 \\
\hline & $22.2 \%$ & $77.8 \%$ & $100.0 \%$ \\
\hline \multirow[t]{2}{*}{ Gentamycin } & 68 & 22 & 90 \\
\hline & $75.6 \%$ & $24.4 \%$ & $100.0 \%$ \\
\hline \multirow[t]{2}{*}{ Imepenem } & 84 & 6 & 90 \\
\hline & $93.3 \%$ & $6.7 \%$ & $100.0 \%$ \\
\hline \multirow[t]{2}{*}{ Levofloxacin } & 16 & 74 & 90 \\
\hline & $17.8 \%$ & $82.2 \%$ & $100.0 \%$ \\
\hline \multirow[t]{2}{*}{ Meropenem } & 66 & 24 & 90 \\
\hline & $73.3 \%$ & $26.7 \%$ & $100.0 \%$ \\
\hline \multirow[t]{2}{*}{ Nitrofurantion } & 87 & 3 & 90 \\
\hline & $96.7 \%$ & $3.3 \%$ & $100.0 \%$ \\
\hline \multirow[t]{2}{*}{ Piperacillin-tazobactam } & 62 & 28 & 90 \\
\hline & $68.9 \%$ & $31.1 \%$ & $100.0 \%$ \\
\hline
\end{tabular}

Table 19: Antibiotic Sensitivity Of Pseudomonas Spp.

\begin{tabular}{|l|l|l|l|}
\hline Antibiotic & Sensitive & Resistant & Total \\
\hline \multirow{2}{*}{ Amikacin } & 5 & 2 & 7 \\
\cline { 2 - 4 } & $71.4 \%$ & $28.6 \%$ & $100.0 \%$ \\
\hline \multirow{2}{*}{ Cefoperazone/salbactam } & 4 & 3 & 7 \\
\cline { 2 - 4 } & $57.1 \%$ & $42.9 \%$ & $100.0 \%$ \\
\hline \multirow{2}{*}{ Cefepime } & 2 & 5 & 7 \\
\cline { 2 - 4 } & $28.6 \%$ & $71.4 \%$ & $100.0 \%$ \\
\hline \multirow{2}{*}{ Gentamycin } & 1 & 6 & 7 \\
\cline { 2 - 4 } & $14.3 \%$ & $85.7 \%$ & $100.0 \%$ \\
\hline \multirow{2}{*}{ Imepenem } & 2 & 5 & 7 \\
\cline { 2 - 4 } & $28.6 \%$ & $71.4 \%$ & $100.0 \%$ \\
\hline \multirow{2}{*}{ Levofloxacin } & 5 & 2 & 7 \\
\cline { 2 - 4 } & $71.4 \%$ & $28.6 \%$ & $100.0 \%$ \\
\hline Meropenem & 1 & 6 & 7 \\
\cline { 2 - 4 } & $14.3 \%$ & $85.7 \%$ & $100.0 \%$ \\
\hline
\end{tabular}

www.worldwidejournals.com $\mid$ 


\begin{tabular}{|l|l|l|l|}
\hline & $42.9 \%$ & $57.1 \%$ & $100.0 \%$ \\
\hline Piperacillin-tazobactam & 5 & 2 & 7 \\
\hline \multirow{2}{*}{ Tobramycin } & $71.43 \%$ & $28.57 \%$ & $100.0 \%$ \\
\hline & 2 & 5 & 7 \\
\cline { 2 - 4 } & $28.6 \%$ & $71.4 \%$ & $100.0 \%$ \\
\hline
\end{tabular}

Table 20: Antibiotic Sensitivity Of Klebsiella Spp.

\begin{tabular}{|c|c|c|c|}
\hline Antibiotic & Sensitive & Resistant & Total \\
\hline \multirow[t]{2}{*}{ Amikacin } & 6 & 4 & 10 \\
\hline & $60.0 \%$ & $40.0 \%$ & $100.0 \%$ \\
\hline \multirow[t]{2}{*}{ Cefoperazone/salbactam } & 4 & 6 & 10 \\
\hline & $40.0 \%$ & $60.0 \%$ & $100.0 \%$ \\
\hline \multirow[t]{2}{*}{ Ciprofloxacin } & 4 & 6 & 10 \\
\hline & $40.0 \%$ & $60.0 \%$ & $100.0 \%$ \\
\hline \multirow[t]{2}{*}{ Cefepime } & 4 & 6 & 10 \\
\hline & $40.0 \%$ & $60.0 \%$ & $100.0 \%$ \\
\hline \multirow{2}{*}{$\begin{array}{l}\text { Trimethoprim- } \\
\text { sulfamethoxazole }\end{array}$} & 6 & 4 & 10 \\
\hline & $60.0 \%$ & $40.0 \%$ & $100.0 \%$ \\
\hline \multirow[t]{2}{*}{ Ceftriaxone } & 2 & 8 & 10 \\
\hline & $20.0 \%$ & $80.0 \%$ & $100.0 \%$ \\
\hline \multirow[t]{2}{*}{ Gentamycin } & 7 & 3 & 10 \\
\hline & $70.0 \%$ & $30.0 \%$ & $100.0 \%$ \\
\hline \multirow[t]{2}{*}{ Imepenem } & 8 & 2 & 10 \\
\hline & $80.0 \%$ & $20.0 \%$ & $100.0 \%$ \\
\hline \multirow[t]{2}{*}{ Levofloxacin } & 2 & 8 & 10 \\
\hline & $20.0 \%$ & $80.0 \%$ & $100.0 \%$ \\
\hline \multirow[t]{2}{*}{ Meropenem } & 6 & 4 & 10 \\
\hline & $60.0 \%$ & $40.0 \%$ & $100.0 \%$ \\
\hline \multirow[t]{2}{*}{ Nitrofurantion } & 6 & 4 & 10 \\
\hline & $60.0 \%$ & $40.0 \%$ & $100.0 \%$ \\
\hline \multirow[t]{2}{*}{ Piperacillin-tazobactam } & 7 & 3 & 10 \\
\hline & $70.0 \%$ & $30.0 \%$ & $100.0 \%$ \\
\hline
\end{tabular}

\section{DISCUSSION:}

An estimated 150 to 250 million individuals worldwide develop urinary tract infection (UTI) every year.UTI is one of the most common infection affecting all age groups including men, women and children worldwide.UTI can affect both lower and upper urinary tract which may be acquired from community or hospital. Out of 800 samples taken up for the study $208(26 \%)$ were culture positive and $592(74 \%)$ were negative, Odoki $\mathrm{M}$ et $\mathrm{al}^{(16)}$ reported almost the same frequency of urinary tract infections (UTIs), 86/267 (32.2\%) in patients attending hospitals with suspected urinary tract infection. In our study among 208 positive samples 125(60.10\%) were females and $83(39.90 \%)$ were males which is similar to the study conducted by Baral Ret $\mathrm{al}^{(1)}$ where female predominance was observed with $71 \%$ whereas $29 \%$ males were affected by UTI. In our study incidence of UTI was predominantly in females of age group (21-40 yrs) $25.48 \%$ with respect males. Strom BL et al ${ }^{(17)}$, Stamm WE et al ${ }^{(18)}$, and Ako-Nai AK et al ${ }^{(19)}$ who have reported the incidence of UTI in adult females much higher about 6 times higher than males of similar age.Our results indicate that the incidence in adult females was higher than males of similar age (2:1) whereas in older age groups of 60 years and above, incidence in male and female were almost same.In our study $15.86 \%$ patients had history of instrumentation which is in similarity with S.A. Ally et $\mathrm{al}^{(20)}$ who reported instrumentation as an important risk factor for UTI. most common organism isolated on culture was Escherichia coli $(43.26 \%)$ both in short stay patients (<48hrs hospital stay) /OPD $22.59 \%$ as well as in IPD (>48hrs hospital stay) $20.67 \%$.

E.coli was isolated from patients of both uncomplicated and complicated UTI. In a similar study by Ahmad $\mathbf{S}^{(21)}$ there was predominance of E.coli among the causative agents of urinary tract infection, supporting the view Pulverers G et al ${ }^{(22)}$, Akbar $\mathrm{DH}^{(23)}$, Rafay $\mathrm{AM}^{(24)}$, Shamweel $\mathrm{A}$ et al ${ }^{(25)}$ also reported $\mathrm{E}$. coli as the most frequent cause of the infection. The reason of highest rate of isolation of $\mathrm{E}$. coli as causative agent of UTI can be explained by the inherent virulence factors of uopathogenic E.coli which include Type 1 fimbriae, P-fimbriae that mediate urinary tract colonization and association with other microorganisms moving from the perianal area contaminated with fecal microbes .The second most common organism isolated in our study was Enterococcus faecalis(22.59\%), the rate of isolation was much higher $18.75 \%$ in inpatients (>48hrs hospital stay) and only $3.84 \%$ in OPD/short stay patients (<48hrs hospital stay) this is in contrast with $\mathrm{S}$. Ahmad ${ }^{(21)}$ who reported Klebsiella pneumonia $22.4 \%$ as a second most common cause of urinary tract infection in Srinagar. In a study conducted by Shamweel and Mubaraki $^{(25)}$ Shamweel and Farooque ${ }^{(26)}$, Ahmed and Ragaa ${ }^{(27)}$, E. coli and Klebsiella pneumoniae accounted for approximately $70 \%$ of the isolates respectively. In our study Enterococcus spp ranked second amongst uropathogens, in IPD patients isolation rate was almost 5 times higher. In most of the patients there was a history of prolonged hospital stay, instrumentation, and catheterization. Prolonged hospital stay is associated with the colonization of the peri-urethral area with Enterococci further prolonged administration of antibiotics result in the overgrowth of the resistant Enterococci and other MDR GNB which than gain entrance to bladder by an ascending route ${ }^{(28)}$.Urinary catheterization induces fibrinogen release into the bladder as part of the inflammatory response; this fibrinogen subsequently accumulates in the bladder and is deposited on the implanted catheter (Flores-Mireles $\mathrm{AL}$ et $\mathrm{al}^{(29)}$. Following fibrinogen deposition, the Ebp pilus adhesin - EbpA, which contains an $\mathrm{N}$-terminal fibrinogen- binding domain - mediates catheter colonization and biofilm formation during UTIs caused by Enterococcus (Nielsen HV, et $\mathrm{al}^{(30)}$ ).Other less frequently isolated organisms in our study included Klebsiella spp 2 $(0.96 \%)$ in OPD and $8(3.84 \%)$ in IPD, Pseudomonas spp was 1 isolate in OPD $(0.48 \%)$ and $6(2.88 \%)$ in IPD, Acinetobacter 3 $(1.44 \%)$, Proteus $1(0.48 \%)$ found only in hospitalized patients (stay $>48 \mathrm{hrs}$ ).

Thus in our study gram negative bacteria were most predominant microorganisms resulting in more than 50\% infections causing urinary tract infection.In our study we have seen that gram positive cocci especially Enterococcus result in UTI in a significant proportion of patients. E.coli showed following sensitivity pattern $96.7 \%$ to nitrofurantoin, $93.3 \%$ to imipenem, $90.0 \%$ to amikacin, $75.6 \%$ to gentamycin, $73.3 \%$ to cefoperazone-salbactam and meropenem both, $68.9 \%$ to pipercillin tazobactam. The sensitivity to TMP-SMX was $45.6 \%$, and to ceftriaxone and cefipime was only $22.2 \%$ and $21.1 \%$ respectively. The organism also showed resistance to drugs like levofloxacin $82.2 \%$ and ciprofloxacin $76.7 \%$. Similar study conducted by Thattil, et al ${ }^{(31)}$ reported sensitivity of E. coli to imipenem as $98.2 \%$ followed by nitrofurantoin $(82.3 \%)$, amikacin $(81.1 \%)$, piperacillin tazobactum $(75.2 \%)$ and cefotaxime $32.2 \%$ and E. coli was least sensitive to naldixic acid (15.5\%). Biswas et $\mathrm{ll}^{(32)}$ found $100 \%$ sensitivity of E. coli to imipenem, meropenem, amikacin and nitrofurantoin followed by gentamycin $94.1 \%$.Enterococcus faecalis isolated in our study was sensitive to Vancomycin $95.74 \%$ followed by Linezolid (93.6\%), Nitrofurantoin (78.7\%), HLAmikacin (74.5\%),HL-Gentamycin (70.2\%). Enterococcus faecalis showed resistance to drugs commonly used to treat UTI i.e. $91.5 \%$ resistant to Ciprofloxacin and $89.4 \%$ resistant to Levofloxacin. Enterococcus spp. have intrinsic resistance to: Cephalosporins, Trimethoprim-sulfamethoxazole, Low or therapeutic concentrations of aminoglycosides ${ }^{(56)}$ so antimicrobial sensitivity for these drugs was not tested whereas AST of high level aminoglycosides was detected by Vitek-2 automated system. In our study all isolates of S.aureus $2.88 \%$ were methicillin resistant and were primarily isolated from IPD patients, and were $100 \%$ sensitive to vancomycin and nitrofurantoin. These isolates also showed resistance to commonly used fluroquinolones like $83.3 \%$ isolates were resistant to ciprofloxacin and levofloxacin. A Study conducted by Reshmi Gopalakrishnan et $\mathrm{al}^{(33)}$ reported that none of the Staphylococcus isolates and Enterococcus spp were vancomycin resistant.Other gram negative organisms

|www.worldwidejournals.com $\mid$ 
isolated in our study were highly resistant to antibiotics like Ciprofloxacin and Levofloxacin including Klebsiella species, $(60 \%$ and $80 \%)$ P. aureginosa (71.4\% and $85.7 \%)$. From the results of our study we suggest nitrofurantoin as the most effective drug for the treatment of UTI as well as for chemoprophylaxis of recurrent UTI caused by both GNB as well as GPC. Other drugs like aminoglycosides, carbepenems, fluroquinolones and linezolid (in GPC) should be reserved for patients with severe illness, keeping in mind other co-morbidities of the patient .Choosing judiciously whether to initiate antibiotic therapy and then selecting the most urinary-focused agent for the shortest appropriate duration are important factors in global efforts to stem the rise of antimicrobial-resistant organisms respectively. The implementation of antibiotic stewardship programs is crucial to minimize resistance. Appropriate antibiotics need to be prescribed based on the antibiotic susceptibility testing which will be narrow spectrum, effective and less expensive with least side effects.

\section{REFERENCES:}

1. Baral R, Maharjan SK. Rapid Nitrite Dipstick Vs Urine culture for diagnosis of Urinary tract Infections (UTI): Laboratory prospective. International Journal of Biomedical Research 2017:8(04):204-209.

2. Fatima A, Jan A, Akhter N, Fomda BA, Lone MS, Ahmed J, Samad L, Roohi S.Evaluation of Microscopic Screening Methods for Detection of Urinary Tract Infection.Int J Cur Res Rev 2017;9(6).

3. Jack D. Sobel, Donald Kaye, Urinary tract infections. Gerald. Mandell John E. Bennett Raphael Dolin Mandell, Douglas and Bennett's Principle and Practice of Infectious diseases 8th edition. Churchill Livingstone Elsevier; 2010.p.886913.

4. Levison ME, Kaye D.Treatment of complicated urinary tract infections with an emphasis on drug- resistant Gram-negative uropathogens. Curr Infect Dis Rep.2013;15:109-115. [PubMed:23378123]

5. Jack D. Sobel, Donald Kaye, Urinary tract infections. Gerald. Mandell John E. Bennett Raphael Dolin Mandell, Douglas and Bennett's Principle and Practice of Infectious diseases 8th edition. Churchill Livingstone Elsevier; 2010.p.886913

6. Hickling D R et al. Anatomy and Physiology of the Urinary Tract: Relation to Host Defense and Microbial Infection. Microbiol Spectr. Author manuscript; available in PMC 2016 February 01

7. Tille, Patricia M. Infections of the Urinary Tract. Bailey and Scott's diagnostic microbiology. Fourteenth edition Churchill Livingstone Elsevier; 2017; p 987998

8. Kalpana Gupta, Barbara W. Trautner.Urinary Tract Infections, Pyelonephritis, and Prostatitis. Jameson, Fauci, Kasper, Hauser, Longo, loscalzo. Harrison's principles of internal medicine. $20^{\text {th }}$ edition. McGraw-Hill Education 2018: $\mathrm{p}$ 968-976

9. Taneja N, Chatterjee SS, Singh M, Sivapriya S, Sharma M, Sharma SK.Validity of Quantitative Unspun Urine Microscopy, Dipstick Test Leucocyte Esterase and Nitrite Tests in Rapidly Diagnosing Urinary Tract Infections. JAPI 2010; 58:485-87.

10. Polat C, Evliyaoglu O, Erkan REC, Ba $\square$ turk A, TugrulÇakır, Aslaner A et al. Comparison of urine microscopy and urine culture results of patients considered to have urinary tract infection. Am J Exp Clin Res. 2015; 2(3): 118 20.

11. Betty AF, Sahm DF, Weissfeld AS. Bailey and Scott's Diagnostic Microbiology, 11 th edition. Philadelphia, Mosby publications; 2004:927-38.

12. Parajuli KP, Chaulagain DD, Singh G, Shrestha M, Chaudhary B, Surendra Chaurasia et al.Diagnosis of urinary tract infection: fresh urine microscopy or culture. Journal of Biomedical and Pharmaceutical Research. 2013; 2(6): 6364

13. Urinary tract infection: an overview of the infection and the associated risk factors.

14. Tiruneh M, Yifru S, Gizachew M, Molla K, Belyhun Y, Moges F et al. Changing Trends in Prevalence and Antibiotics Resistance of Uropathogens in Patients Attending the Gondar University Hospital, Northwest Ethiopia. International Journal of Bacteriology. 2014

15. Clinical and Laboratory Standards Institute. Performance Standards for Antimicrobial Susceptibility Testing: Twenty seventh Informational Supplement. CLSI document M100-S27. Wayne, Pa: Clinical and Laboratory Standard Institute; 2017

16. Odoki M et al.Prevalence of Bacterial Urinary Tract Infections and Associated Factors among Patients Attending Hospitals in Bushenyi District, Uganda.Hindawi International Journal of Microbiology Volume 2019, Article ID 4246780,8 pages https://doi.org/10.1155/2019/4246780.

17. Strom BL, Collins M, West SL, Kreisberg J, Weller S. Sexual activity, contraceptive use and other risk factors for symptomatic and asymptomatic bacteriuria. Ann Intern Med 1987; 107:816-823

18. W.E.Stamm and S.R. Norrby, "Urinary tract infections: disease panorama and challenges,"Journal of Infectious Diseases, vol. 183, no.s1,pp.S1-S4,2001.

19. Ako-Nai AK, Kassim OO, Adenitan MO, Taiwo O. A study of urinary tract infections at ILE-IFE, Nigeria. East Afr Med J 1993; 70: 10-14.

20. A.Hoberman,M.Charron, R.W.Hickey,M.Baskin,D.H.Kearney, and E.R.Wald, "Imaging studies after a $\square$ rst febrile urinary tract infection in young children," New En- gland Journal of Medicine, vol. 348, no. 3, pp.195-202, 2003.

21. Ahmad S.Pattern of urinary tract infection in Kashmir and antimicrobial susceptibility.Bangladesh Med Res Counc Bull.2012 Dec;38(3):79-83.

22. Pulverers $\mathrm{G}$, Cho $\mathrm{C} \mathrm{H}$, Spikeman $\mathrm{C} \mathrm{H}$. Etiology of pyogenic urinary tract infections in the region in Bayer symposium III. Bacterial infections, changes in their casual agents, trends and possible basis, pp 25-29; 1971. Springer- verlag, Berlin, Heidelberg.New York.

23. Akbar DH. Urinary tract infection. Diabetics and non- diabetic patients. Saudi Medical Journal 2001;Vol.22 (4):326-329.

24. Rafay AM. Urinary tract infections in general practice in a rural community in South Trinidad. Saudi Medical Journal 2003;Vol.24 (3):261-264.

25. Shamweel A, Mubaraki AM. Antimicrobial Susceptibility of Gram Negative Organisms in Urine Cultures at Armed Forces Hospital in Saudi Arabia. Dis J Pak2011;20(4):357-360.

26. Shamweel A, Ahmad F. Urinary tract infection at a specialist hospital in Saudi Arabia. Bangladesh Med. Res. Counc.Bull. 1995;21(3):95-98.

27. Ahmed T, Eltahawy Ragaa MF.Khalaf. Urinary tract infection at University hospital in Saudi Arabia: incidence, microbiology, and antimicrobial susceptibility. Annals of Saudi Medicine 1988;8(4):261-266.

28. Cesar A. Arias and Barbara E. Murray. Enterococcus Species, Streptococcus gallolyticus Group, and Leuconostoc Species. Gerald. Mandell John E. Bennett Raphael Dolin Mandell, Douglas and Bennett's Principle and Practice of Infectious diseases 8th edition. Churchill Livingstone Elsevier; 2015.p.2330.

29. Flores-Mireles et al. Urinary tract infections: epidemiology, mechanisms of infection and treatment options. Nat Rev Microbiol.2015 May; 13(5):269-284.

30. Nielsen HV, et al. Pilin and sortase residues critical for endocarditis- and biofilm-associated pilus biogenesis in Enterococcus faecalis. J Bacteriol. 2013; 195:4484-4495. [PubMed:23913319]

31. Thattil S J et al.Prevalence of UTI in Different Age Groups in a Tertiary Care Hospital and their Antibiogram. International Journal of Contemporary Medical Research ISSN (Online):2393-915X; (Print):2454-7379 | ICV:77.83 | Volume 5 | Issue 1 | January 2018

32. Biswas R, Rabbani, Ahmed H S, Sarker M A, Zafrin N, Rahman M M. Antibiotic sensitivity pattern of urinary tract infection at a tertiary care hospital. Bangladesh crit. Care J 2014;2:21 - 24 .

33. Rreshmi Gopalakrishnan, B.V. Chandrasekharamurthy, bacteriological profile and antibiogram of uropathogens among antenatal cases in a tertiary care hospital Indian J microbial res 201 7;4:333-337. 